\title{
Phenolics in Human Health
}

\author{
T. Ozcan, A. Akpinar-Bayizit, L. Yilmaz-Ersan, and B. Delikanli
}

\begin{abstract}
Recent research focuses on health benefits of phytochemicals, especially antioxidant and antimicrobial properties of phenolic compounds, which is known to exert preventive activity against infectious and degenerative diseases, inflammation and allergies via antioxidant, antimicrobial and proteins/enzymes neutralization/modulation mechanisms. Phenolic compounds are reactive metabolites in a wide range of plant-derived foods and mainly divided in four groups: phenolic acids, flavonoids, stilbenes and tannins. They work as terminators of free radicals and chelators of metal ions that are capable of catalyzing lipid oxidation. Therefore, this review examines the functional properties of phenolics.
\end{abstract}

Index Terms-Health, functional, phenolic compounds.

\section{INTRODUCTION}

In recent years, fruits and vegetables receive considerable interest depending on type, number, and mode of action of the different components, so called as "phytochemicals", for their presumed role in the prevention of various chronic diseases including cancers and cardiovascular diseases. Plants are rich sources of functional dietary micronutrients, fibers and phytochemicals, such as ascorbic acid, carotenoids, and phenolic compounds, that individually, or in combination, may be beneficial for health since they demonstrate antioxidative activity in vitro [1]-[4].

Phenolics, possess an aromatic ring bearing one or more hydroxyl groups and their structures may range from that of a simple phenolic molecule to that of a complex high-molecular weight polymer, are widespread groups of substances in flowering plants, occurring in all vegetative organs, as well as in flowers and fruits, vegetables, cereals, grains, seeds and drinks. Despite this structural diversity, the groups of compounds are often referred to as "polyphenols". They are secondary metabolites which are derived from pentose phosphate, shikimate, and phenylpropanoid pathways in plants [5]-[7]. Plant genetics and cultivar, soil composition and growing conditions, maturity state and post-harvest conditions are effective on the quantity and quality of the polyphenols present in plant foods [8]. Phenolic compounds can basically be categorized into several classes as shown in Fig. 1.

Aside with being responsible for the color (such as yellow, orange, red, and blue pigments), taste and flavor (such as vanillin and eugenol) of foods one of the major polyphenol characteristics is radical-scavenging capacity, which is involved in antioxidant properties, and the ability to interact

Manuscript received November 20, 2013; revised February 21, 2014.

The authors are with Department of Food Engineering, Faculty of Agriculture, Uludag University, Bursa, Turkey (e-mail: tulayozcan@uludag.edu.tr; abayizit@uludag.edu.tr; lutfiyey@uludag.edu.tr; berrakdelikanli@gmail.com). with proteins. The high antioxidant capacity makes polyphenols as an important key factor which is involved in the chemical defense of plants against pathogens and predators and in plant-plant interferences [9].

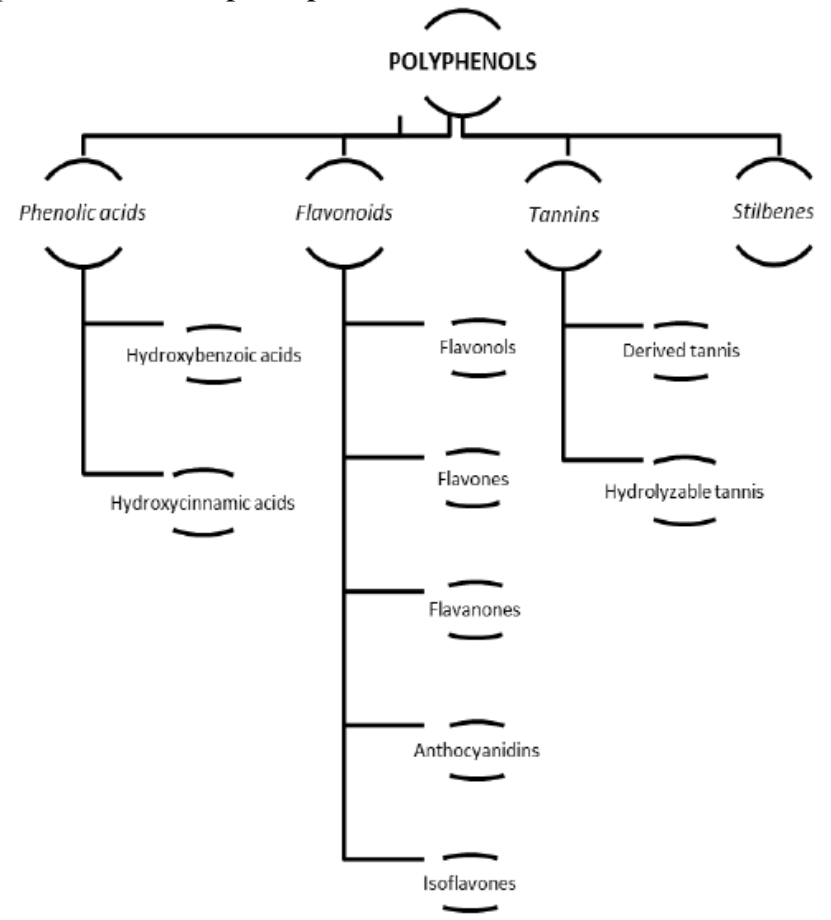

Fig. 1. Main classes of polyphenolic compounds.

\section{A. Phenolic Acids}

Phenolic acids consist of two subgroups: the hydroxybenzoic and hydroxycinnamic acids.Hydroxybenzoic acids include gallic, $p$-hydroxybenzoic, protocatechuic, vanillic and syringic acids, which in common have the C6-C1 structure. Hydroxycinnamic acids, on the other hand, are aromatic compounds with a three-carbon side chain (C6-C3), with caffeic, ferulic, $p$-coumaric and sinapic acids being the most common. The main sources of phenolic acids are blueberry, cranberry, pear, cherry (sweet), apple, orange, grapefruit, cherry juice, apple juice, lemon, peach, potato, lettuce, spinach, coffee beans, tea, coffee and cider. Hydroxycinnamic acids are a major class within the phenolic compounds [10], [11].

\section{B. Flavonoids}

Flavonoids are the most abundant polyphenols in human diets, accounting for over half of the eight thousand naturally occurring phenolic compounds found mainly in blackberries, black currant, blueberries, grape, strawberries, cherries, plums, cranberry, pomegranate, and raspberry. They are low molecular weight compounds, consisting of fifteen carbon atoms; bear the C6-C3-C6 structure. They are mainly divided into two classes: (a) anthocyanins (glycosylated derivative of anthocyanidin, present in colorful flowers and fruits); (b) anthoxanthins (a group of colorless compounds further 
divided in several categories, including flavones, flavans, flavonols, isoflavones and their glycosides) [10], [12]-[14].

\section{Tannins}

Tannins, the relatively high molecular weight compounds found in complexes with alkaloids, polysaccharides and proteins, are a group of water-soluble polyphenols. They may be subdivided into hydrolysable and condensedtannins. The hydrolysable tannins are esters ofgallic acid (gallo- and ellagi-tannins), while the condensed tannins(also known as proanthocyanidins) are polymers of polyhydroxyflavan-3-ol monomers. A third subdivision, the phlorotannins consisting entirely of phloroglucinol, has been isolated from several genera of brown algae. They are found grape (dark/light) seed/skin, apple juice, strawberries, raspberries, pomegranate, walnuts, muscadine grape, peach, blackberry, olive, plum, chick pea, black-eyed peas, lentils, haricot bean, red/white wine, cocoa, chocolate, tea, cider, coffee, immature fruits are the main sources of tannins [10]-[15].

\section{Stilbenes}

Stilbenes are structurally characterized by the presence of a 1,2-diphenylethylene nucleus with hydroxyl groups substitued on the aromatic rings. They exist in the form of monomers or oligomers. The best known compound is trans-resveratrol, possessing a trihydroxystilbene skelelton [16]. The major dietary sources of stilbenes include grapes, wine, soy, peanuts, and peanut products [17].

\section{PolyphenOls In HeAlth}

The possible health benefits of dietary phenolics depend on their absorption and metabolism, which in turn are determined by their structure including their conjugation with other phenolics, degree of glycosilation/acylation, molecular size and solubility. These steps occur at various points during passage through the wall of the small intestine into the circulatory system and subsequent transport to the liver in the portal vein. The metabolites of polyphenols are rapidly eliminated from plasma, thus, daily consumption of plant products is essential in order to supply high metabolite concentrations in the blood [18]-[21]. However, one should keep in mind that the most abundant polyphenols in daily diet are not necessarily those that have the best bioavailability. For example hydroxycinnamic acids are found at high concentrations in foods but esterification decreases their intestinal absorption. The bioavailability of phenolic compounds can also be affected by differences in cell wall structures, location of glycosides in cells and binding of phenolic compounds within the food matrix [22]-[26].

Upto now epidemiological knowledge emphasize that polyphenols display important functions, like inhibition of pathogens and decay microorganisms, anti-deposition of triglycerides, reduce the incidence of non-communicable diseases such as cardiovascular diseases, diabetes, cancer and stroke, anti-inflammation and anti-allergic effect through processes involving reactive oxygen species. These protective effects are attributed, in part, to phenolic secondary metabolites [26]-[28]. Initially, the protective effect of dietary phenolics was thought to be due to their antioxidant properties which are the lowering of the levels of free radicals present in the body. However, there is now emerging evidence that the metabolites of dietary phenolics, which appear in the circulatory system in $\mathrm{nmol} / \mathrm{L}$ to low $\mathrm{mmol} / \mathrm{L}$ concentrations, exert modulatory effects in cells through selective actions on different components of the intracellular signaling cascades vital for cellular functions such as growth, proliferation and apoptosis [18]. Polyphenols is thought to display their antioxidant capacity, depending on the hydroxylation status of their aromatic rings, including (i) scavenging of free radicals, (ii) chelation and stabilization of divalent cations, and (iii) modulation of endogenous antioxidant enzymes [29]-[31].

Phenolic acids, hydrolysable tannins, and flavonoids have anti-carcinogenic and anti-mutagenic effects since they act as protective agents of DNA against free radicals, by inactivating carcinogens, inhibiting enzymes involved in pro-carcinogen activation and by activating of xenobiotics detoxification enzymes. In particular flavonoids and $L$-ascorbic acid have a synergistic protective effect towards oxidative damages of DNA in lymphocytes [32]-[34]. Block et al. [35] stated that a diet rich in vegetables reduces the risk for colon cancer. Both chlorogenic and caffeic acids are antioxidants in vitro, and they are potential inhibitors for the formation of mutagenic and carcinogenic $N$-nitroso compounds in vitro [36].

Flavonoids, catechins and their derivatives are considered as therapeutic agents in studies focused on degenerative diseases and brain aging processes, and serve as possible neuroprotective agents in progressive neurodegenerative disorders such as Parkinson's and Alzheimer's diseases [37]-[40]. High flavonoid intakes lead a decrease in LDL oxidation [41], [42].

Resveratrol, trans-3,5,4'-trihydroxystilbene, is the best known health promoting molecule in grapes and red wine, and has been studied for its effects on genes as well as the heart, breast, prostate, uterus, and immune system. In addition, recent studies show that resveratrol sustains healthy nerves and important brain functions including cognitive processes [43]-[46].

Tannins, commonly referred as tannic acid, have been reported to be responsible for decreases in feed intake, growth rate, feed efficiency, net metabolizable energy, and protein digestibility in experimental animals. Therefore, tannins-rich foods, such as betel nuts and herbal teas, are considered to be of low nutritional value. However, many researches indicated that the major effect of tannins was not due to their inhibition on food consumption or digestion but rather the decreased efficiency in converting the absorbed nutrients to new body substances. The anticarcinogenic and antimutagenic potentials of tannins may be related to their antioxidative property, which is important in protecting cellular oxidative damage, including lipid peroxidation. Tannins have also been reported to exert other physiological effects, such as to accelerate blood clotting, reduce blood pressure, decrease the serum lipid level, produce liver necrosis, and modulate immunoresponses [47], [48].

Polyphenols (phenolic acid, stilbenes, tannins, isoflavones green tea catechins) have been reported to inhibit the reproduction and growth of many fungi, yeasts, viruses and 
bacteria, such as Salmonella, Clostridium, Bacillus or Chlamydia pneumoniae Vibrio cholerae Enterotoxigenic E. coli (ETEC). This antimicrobial property of phenolics can be used in food processing to increase the shelf-life of certain foods, such as catfish fillets, since they serve as a natural defense mechanism against microbial infections [49]-[52].

\section{CONCLUSION}

In recent years there is an upsurge in the food industry related to newer developments about the role of phenolic component as antioxidant, anti-mutagenic, and scavenging activity on free radicals and prevention of pathologies such as cancer and cardiovascular heart disease. The majority of data on health benefits of polyphenols-rich diet is still observational, and some are contradictory. Some epidemiologic studies have indicated a negative correlation between consumption of polyphenols with diet and the risk of infectious, degenerative and chronic diseases. There are limited information on potential adverse effects which suggest that some phenolic compounds, when ingested at high concentrations may exhibit roles in genotoxicity, thyroid toxicity, interaction with pharmaceuticals, and estrogenic activity. Nevertheless, most researchers stated that the health effects of polyphenols depend on the amount consumption and on their bioavailability leading more controlled and clinical studies.

\section{REFERENCES}

[1] R. H. Liu, "Potential synergy of phytochemicals in cancer prevention: Mechanism of action," Journal of Nutrition, vol. 134, pp. 3479-3485, 2004.

[2] K. W. Syngletary, S. J. Jackson, and J. A. Milner, "Non-nutritive components in foods as modifiers of the cancer process," in Preventive Nutrition: the Comprehensive Guide for Health Professionals, A. Bendich and R. J. Deckelbaum, Ed., 3rd ed. Totowa, N.J.: Humana Press, 2005, pp. 55-88.

[3] S. S. Percival, S. T. Talcott, S. T. Chin, A. C. Mallak, A. Lound-Singleton, and J. Pettit-Moore, "Neoplastic transformation of BALB/3T3 cells and cell cycle of HL-60 cells are inhibited by mango (Mangifera indica L.) juice and mango juice extract," Journal of Nutrition, vol. 136, pp. 1300-1304, 2006.

[4] E. M. Yahia, "The contribution of fruit and vegetable consumption to human health," in Phytochemical: Chemistry, Nutritional and Stability, Wiley- Blackwell, 2009, ch. 1, pp. 3-51.

[5] G. G. Duthie, S. J. Duthie, and J. A. M. Kyle, "Plant polyphenols in cancer and heart disease: implications as nutritional antioxidants," Nutrition Research Review, vol. 13, pp. 79-106, 2000.

[6] A. Escarpa, and M. C. Gonzalez, "An overview of analytical chemistry of phenolic compounds in foods," Critical Reviews in Analytical Chemistry, vol. 318, pp. 57-139, 2001.

[7] G. Pinto, and A. Pollio, "Plant polyphenols and their anti-cariogenic properties," Molecules, vol. 16, pp. 1486-1507, 2011.

[8] E. H. Jaffery, A. F. Brown, A. C. Kurilich, A. S. Keek, N. Matusheski, and B. P. Klein, "Variation in content of bioactive components in broccoli," Journal of Food Composition and Analysis, vol. 16, pp. 323-330, 2003.

[9] R. A. Dixon and N. L. Paiva, "Stress-induced phenylpropanoid metabolism," Plant Cell, vol. 7, pp. 1085-1097, 1995.

[10] N. Balasundram, K. Sundram, and S. Samman, "Phenolic compounds in plants and agri-industrial by-products: Antioxidant activity, occurrence, and potential uses," Food Chemistry, vol. 99, pp. 191-203, 2006.

[11] M. P. Gonthier, C. Remesy, A. Scalbert, V. Cheynier, J. M. Souquet, K. Poutanen, and A. M. Aura, "Microbial metabolism of caffeic acid and its esters chlorogenic and caftaric acids by human faecal microbiota in vitro," Biomedicine \& Pharmacotherapy, vol. 60, pp. 536-540, 2006.
[12] C. A. Rice-Evans, N. J. Miller, and G. Paganga, "Antioxidant properties of phenolic compounds," Trends in Plant Science, vol. 2, pp. 152-159, 1997.

[13] S. M. Henning, Y. Niu, Y. Liu, N. H. Lee, Y. Hara, G. D. Thames, R. R. Minutti, C. L. Carpenter, H. Wang, and D. Heber, "Bioavailability and antioxidant effect of epigallocatechin gallate administered in purified form versus as green tea extract in healthy individuals," Journal of Nutrition Biochemistry, vol. 16, pp. 610-616, 2005.

[14] S. B. Lotito and B. Frei, "Consumption of flavonoid-rich foods and increased plasma antioxidant capacity in humans: Cause, consequence, or epiphenomenon?" Free Radical Biology and Medicine, vol. 4, pp. 1727-1746, 2006.

[15] N. Rangkadilok, S. Sitthimonchai, L. Worasuttayangkurn, C. Mahidol, M. Ruchirawat, and J. Satayavivad, "Evaluation of free radical scavenging and antityrosinase activities of standardized longan fruit extract," Food and Chemical Toxicology, vol. 45, pp. 328-336, 2007.

[16] X. Han, T. Shen, and H. Lou, "Dietary polyphenols and their biologica significance," International Journal Molecular Sciences, vol. 8, pp. 950-988, 2007.

[17] A. Cassidy, B. Hanley, and R. M. Lamuela-Raventos, "Isoflavone, lignans and stilbenes-origins, metabolism and potential importance to human health," Journal of the Science and Food Agriculture, vol. 80, pp. 1044-1062, 2000.

[18] A. A. Crozier, I. B. Jaganath, and M. N. Clifford, "Dietary phenolics: chemistry, bioavailability and effects on health," Natural Product Reports, vol. 26, pp. 1001-1043, 2009.

[19] A. J. Parr and G. P. Bolwell, "Phenols in the plant and in man.The potential for possible nutritional enhancement of the diet by modifying the phenols content or profile," Journal of the Science of Food and Agriculture, vol. 80, pp. 985-1012, 2000.

[20] L. Bravo, "Polyphenols: chemistry, dietary sources, metabolism, and nutritional significance," Nutrition Reviews, vol. 56, pp. 317-333, 1998.

[21] C. Manach, G. Williamson, C. Morand, A. Scalbert, and C. Rémésy, "Bioavailability and bioefficacy of polyphenols in humans," American Journal of Clinical Nutrition, vol. 81, pp. 230-242, 2005.

[22] A. J. Parr and G. P. Bolwell, "Phenols in the plant and in man. The potential for possible nutritional enhancement of the diet by modifying the phenols content or profile," Journal of Agricultural and Food Chemistry, vol. 80, pp. 985-1012, 2000.

[23] J. Wollgast and E. Anklam, "Polyphenols in chocolate: is there a contribution to human health?" Food Research International, vol. 33, pp. 449-459, 2000.

[24] L. R. Ferguson, "Role of plant polyphenols in genomic stability," Mutation Research, vol. 475, pp. 89-111, 2001.

[25] G. K. Jayaprakasha, T. Selvi, and K. K. Sakaria, "Antibacterial and antioxidant activities of grape (Vitis vinifera) seed extracts," Food Research International, vol. 36, pp. 117-122, 2003.

[26] M. R. Alberto, C. Gómez-Cordovés, and M. C. Manca De Nadra, "Metabolism of gallic acid and catechin by Lactobacillus hilgardii from wine," Journal Agriculture and Food Chemistry, vol. 52, pp. 6465-6469, 2004.

[27] T. Shoji, M. Mutsuga, T. Nakamura, T. Kanda, H. Akiyama, and Y. Goda, "Isolation and structural elucidation of some procyanidins from apple by low-temperature NMR," Journal of Agricultural and Food Chemistry, vol. 5, pp. 3806-3813, 2003.

[28] B. A. Graf, P. E. Milbury, and J. B. Blumberg, "Flavonols, flavones, flavanones, and human health: Epidemiological evidence," Journal of Medicinal Food, vol. 8, pp. 281-290, 2005.

[29] J. A. Ross, and C. M. Kasum, "Dietary flavonoids: Bioavailability, metabolic effects, and safety," Annual Reviews of Nutrition, vol. 22, pp. 19-34, 2002.

[30] M. A. Soobrattee, T. Bahorun, and O. I. Aruoma, "Chemopreventive actions of polyphenolic compounds in cancer," Biofactors, vol. 27, pp. 19-35, 2006

[31] S. Ramos, "Cancer chemoprevention and chemotherapy: Dietary polyphenols and signaling pathways," Molecular Nutrition and Food Research, vol. 52, pp. 507-526, 2008.

[32] M. Noroozi, W. J. Angerson, and M. E. J. Lean, "Effects of flavonoids and vitamin C on oxidative DNA damage to human lymphocytes," American Journal of Clinical Nutrition, vol. 67, pp. 1210-1218, 1998

[33] L. Bravo, "Polyphenols: chemistry, dietary sources, metabolism and nutritional significance," Nutrition Research Review, vol. 56, pp. 317-333, 1998.

[34] D. Lairon and M. J. Amiot, "Flavonoids in food and natural antioxidants in wine," Current Opinion Lipidology, vol. 10, pp. 23-28, 1999. 
[35] G. Block, B. Patterson, and A. Subar, "Fruit, vegetables, and cancer prevention: A review of the epidemiological evidence," Nutrition and Cancer, vol. 18, pp. 1-29, 1992.

[36] L. I. Mennen, R. Walker, C. Bennetau-Pelissero, and A. Scalbert, "Risks and safety of polyphenol consumption," American Journal of Clinical Nutrition, vol. 81, pp. 326-329, 2005.

[37] F. Yang, W. J. De Villiers, C. J. McClain, and G. W. Varilek, “Green tea polyphenols block endotoxin-induced tumor necrosis factor-production and lethality in a murine model," Journal of Nutrition, vol. 128, pp. 2334-2340, 1998.

[38] E. Tedeschi, M. Menegazzi, Y. Yao, H. Suzuki, U. Forstermann, and H. Kleinert, "Green tea inhibits human inducible nitric-oxide synthase expression by down-regulating signal transducer and activator of transcription-1alpha activation," Molecular Pharmacology, vol. 65, pp. 111-120, 2004.

[39] O. Weinreb, S. Mandel, T. Amit, B. Moussa, and H. Youdim, "Neurological mechanisms of green tea polyphenols in Alzheimer's and Parkinson's diseases," The Journal of Nutritional Biochemistry, vol. 15, pp. 506-516, 2004.

[40] Q. Dai, A. R. Borenstein, and Y. Wu, "Fruit and vegetable juices and Alzheimer's disease: the Kame project," American Journal of Clinical Nutrition, vol. 119, pp. 751-759, 2006.

[41] L. J. Appel, T. J. Moore, and E. Obarzanek, "A clinical trial of the effects of dietary patterns on blood pressure," The New England Journal of Medicine, vol. 336, pp. 1117-1124, 1997.

[42] R. J. Williams, J. P. E. Spencer, and C. Rice-Evans, "Flavonoids: Antioxidants or signalling molecules?" Free Radical Biology and Medicine, vol. 36, pp. 838-849, 2004.

[43] S. Dore, "Unique properties of polyphenol stibenes in the brain: more than direct antioxidant actions; gene/protein regulatory activity," Neurosignals, vol. 14, pp. 61-70, 2005.

[44] T. S. Anekonda, "Resveratrol - a boon for treating Alzeimers disease." Brain Research Reviews, vol. 52, no. 2, pp. 316-326, 2006.

[45] H. Zhuang, Y. S. Kim, R. C. Koehler, and S. Dore, "Potential mechanism by which resveratrol, a red wine constituent, protects neurons," Annals of the New York Academy of Sciences, vol. 993, pp. 276-286, 2003.

[46] Z. Wang, Y. Huang, J. Zou, K. Cao, Y. Xu, and J. M. Wu, “ Effects of red wine and wine polyphenol resveratrol on platelet aggregation in vivo and in vitro," International Journal of Molecular Medicine, vol. 9, no. 1, pp. 77-79, 2002.

[47] K. T. Chung, T. Y. Wong, C. I. Wei, Y. W. Huang, and Y. Lin, "Tannins and human health: a review," Critical Reviews in Food Science and Nutrition, vol. 38, pp. 421-464, 1998.

[48] T. Okuda, "Tannins, a new family of bio-active natural organic compounds questions and answers," Yakugaku Zasshi, vol. 115, pp. 81-100, 1995.

[49] C. Cabrera, R. Artacho, and R. Giménez, "Beneficial effects of green tea," Journal of the American College of Nutrition, vol. 25, pp. 79-99, 2006.

[50] J. Alvesalo, H. Vuorela, P. Tammela, M. Leinonen, P. Saikku, and P. Vuorela, "Inhibitory effect of dietary phenolic compounds on Chlamydia pneumoniae in cell cultures," Biochemical Pharmacology, vol. 71, pp. 735-741, 2006.

[51] N. Morinaga, Y. Iwamaru, K. Yahiro, M. Tagashira, J. Moss, and M. Noda, "Differential activities of plant polyphenols on the binding and internalization of cholera toxin in vero cells," Journal of Biological Chemistry, vol. 280, pp. 23303-23309, 2005.

[52] A. B. Howell, "Bioactive compounds in cranberries and their role in prevention of urinary tract infections," Molecular Nutrition and Food Research, vol. 51, pp. 732-737, 2007.

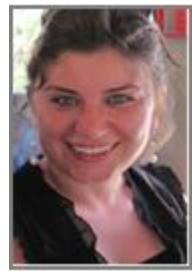

Berrak Delikanli is a postgraduate student of Department of Food Engineering at the Uludag University, Bursa, Turkey. More recently, she has worked in the area of texture of dairy products. Her areas of interest include dairy chemistry and biochemistry, the use of dairy based proteins for the production of functional dairy products. 